\title{
Reading between the joints-using spinal magnetic resonance imaging for evaluation of instability
}

Komal Naeem

Aga Khan University, komal.naeem@aku.edu

\section{S. Ather Enam}

Aga Khan University, ather.enam@aku.edu

Follow this and additional works at: https://ecommons.aku.edu/pakistan_fhs_mc_surg_neurosurg

Part of the Neurology Commons, Neurosurgery Commons, and the Surgery Commons

\section{Recommended Citation}

Naeem, K., Enam, S. (2017). Reading between the joints-using spinal magnetic resonance imaging for evaluation of instability. World Neurosurgery, 107, 1033-1034.

Available at: https://ecommons.aku.edu/pakistan_fhs_mc_surg_neurosurg/73 


\section{Reading Between the Joints-Using Spinal Magnetic Resonance Imaging for Evaluation of Instability}

\section{Komal Naeem and Syed Ather Enam}

Magnetic resonance imaging (MRI) is one of the most common investigations ordered for the evaluation of back and leg pain. Usually, supine MRI is one of the initial tests for the screening of degenerative spine diseases and lumbar spinal stenosis. It is useful for assessing disease severity, involvement of the spine and its surrounding structures, and making decisions about surgery. With all of these advantages in hand, the role of MRI is considered limited in a few aspects-one is the determination of instability. Traditional MRI in a supine position limits the ability of evaluating spondylolisthesis, as vertebral translation is altered by the supine position due to elimination of gravitational pull. Thus dynamic studies like radiographs, dynamic 3-dimensional computed tomography scans, or dynamic MRIs are considered the investigations of choice for measuring vertebral instability. ${ }^{\mathrm{I}-3}$ Several studies have depicted that performing arthrodesis along with laminectomy for patients presenting with spondylolisthesis have shown better functional outcomes as compared with laminectomy alone. For this reason, evaluating spinal stability plays a vital role in deciding therapeutic measures. ${ }^{2,3}$

The facet joint is a synovial joint, and like any other synovial joint (e.g., knee and hip joints) the synovial membrane produces fluid in reaction to joint degeneration. As the patient lies down, the joints open up and this fluid collects in the facet joint, which can be seen in the supine MRI. ${ }^{\mathrm{I}}$ Other degenerative changes such as disk height and facet degeneration have been studied and found to have a significant correlation with spinal instability. ${ }^{2,3}$

Recently, Snoddy et $\mathrm{al}^{4}$ published an article studying the role of MRI in the assessment of spondylolisthesis. They stated that certain findings on MRI indicate spinal instability. A retrospective analysis was done on prospectively collected data from Ioo patients. Snoddy's group hypothesized that the presence of increased fluid between the facet joint on T2-weighted MRI sequences correlates with listhesis seen on dynamic imaging (i.e., standing lateral flexion-extension radiographs). They also studied correlation of disk height with the instability and whether presence of facet fluid serves as a predictor of improvement in back and leg pain at I2 months' follow-up. Facet fluid $>0.9 \mathrm{~mm}$ on T2-weighted sequence of MRI was considered positive (Figure 1). A change of $>3 \mathrm{~mm}$ in the slip of a vertebral body between flexion and extension radiographs was considered positive (Figure 2). The researchers reported a positive correlation between the presence of facet fluid and spondylolisthesis $(\mathrm{P}=0.03)$. For every $\mathrm{I}-\mathrm{mm}$ increase in the facet fluid, the chance of instability increases by 4 I. $6 \%$. Fluid measuring $\leq 0.5 \mathrm{~mm}$ gives $90 \%$ probability that instability is not present. Similarly, a significant inverse relation was reported between the disk height and spinal instability $(\mathrm{P}=0.04)$. For every $\mathrm{I}-\mathrm{mm}$ increase in facet joint fluid, there was a $0.4-\mathrm{mm}$ decrease in disk height. However, no significant relationship was found for instability and disk height $<3 \mathrm{~mm}(\mathrm{P}=0.77)$. The presence of facet fluid and dynamic instability were found to have significant correlation with improvement in back and leg pain at 12 months' follow-up (P values 0.04 and 0.05 , respectively). Functional outcomes were compared for single-level fusion for static versus dynamic instability, and they did not show any significant difference.

In addition to this recent study, there have been other studies establishing the correlation between facet fluid and spinal instability. ${ }^{\mathrm{I}-3,5-7}$ Mailleux et $\mathrm{al}^{8}$ identified the presence of facet fluid as a marker of spinal instability for the first time in 1998 . They reported 2 case reports where they missed listhesis on MRI due to reduction of vertebral slip in the supine position. They observed increased facet fluid in the involved lumbar levels. ${ }^{8}$ This relation was formally studied by Chaput et al in 2007 for the first time. They found that large facet joint effusions were highly predictive of spinal instability (P value o.00or). Logistic regression showed that a $\mathrm{I}-\mathrm{mm}$ increase in facet fluid increases the odds of spondylisthesis by 5.6 fold. ${ }^{\mathrm{I}}$ Rihn et $\mathrm{al}^{2}$ calculated the facet fluid index instead of just facet fluid width. The facet fluid index took facet joint length into account as well and was calculated as the ratio between the synovial fluid width and the facet joint length. They reported a positive predictive value of $82 \%$ for facet fluid on MRI as a predictor of radiographic instability. ${ }^{2}$

Accurate evaluation of instability on MRI can have several implications. It can alter the sequence of imaging studies ordered when evaluating back and leg pain because MRI is usually the first study ordered. Presence or absence of facet fluid will help clinicians to make improved decisions on ordering dynamic studies so

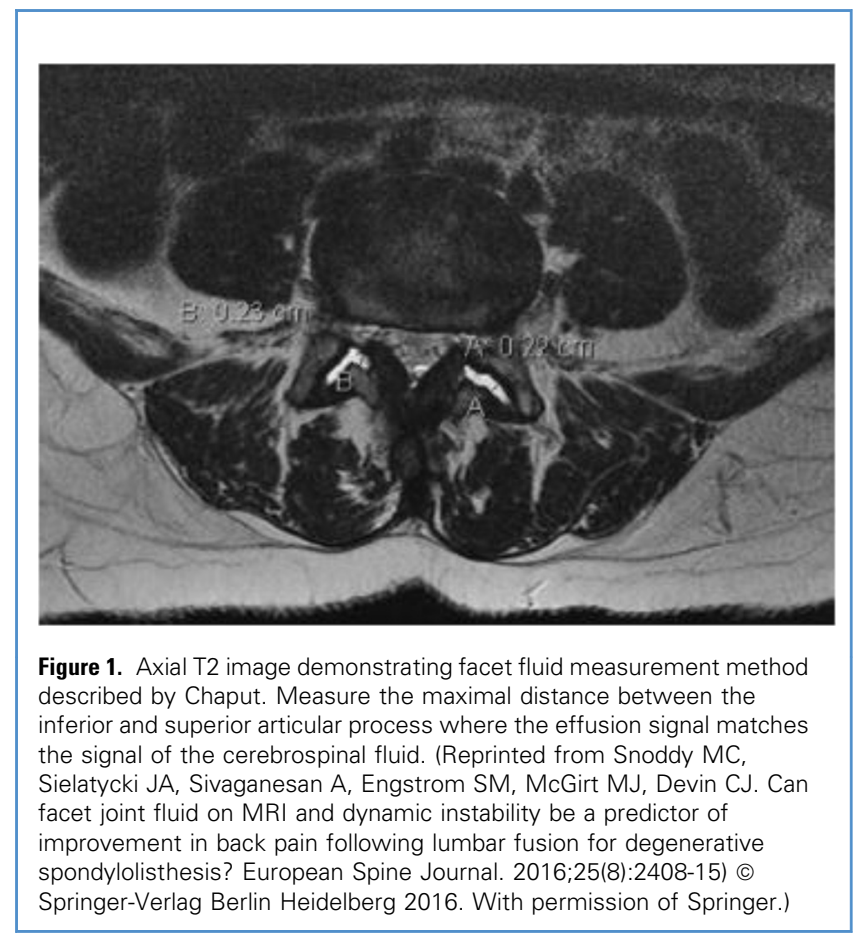




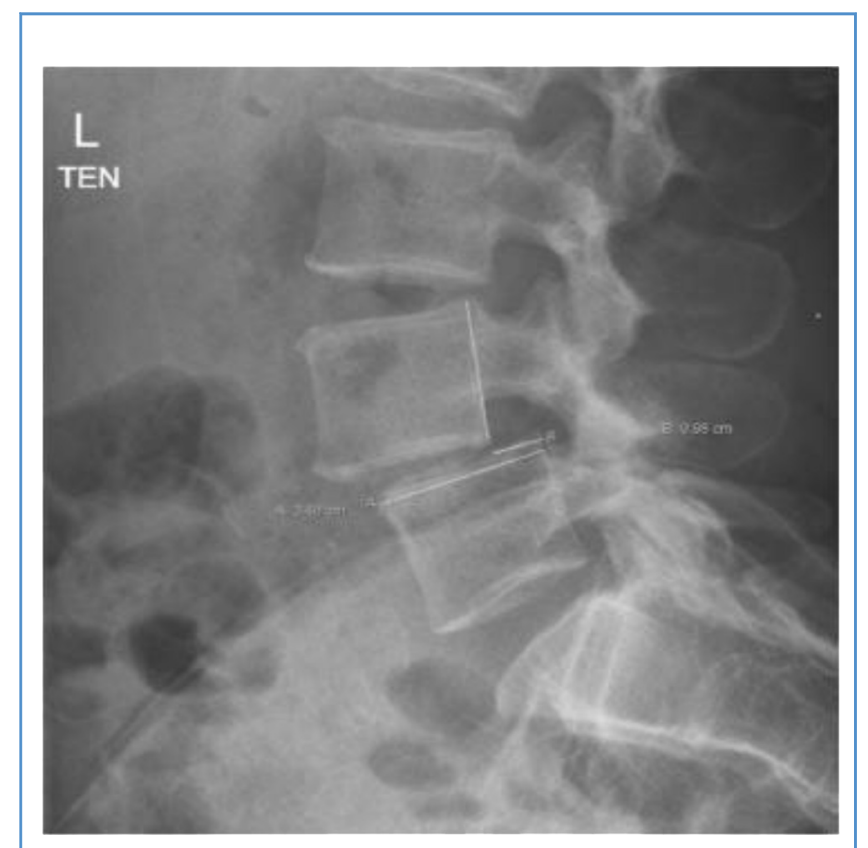

Figure 2. Lateral lumbar radiograph demonstrating slip percentage measurement method described by Boden. For this example, slip distance is $0.98 \mathrm{~cm}$. The superior end plate of the inferior vertebral body measures $3.46 \mathrm{~cm}$. The slip percentage is $28.3 \%(0.98 / 3.46)$. (Reprinted from Snoddy MC, Sielatycki JA, Sivaganesan A, Engstrom SM, McGirt MJ, Devin CJ. Can facet joint fluid on MRI and dynamic instability be a predictor of improvement in back pain following lumbar fusion for degenerative spondylolisthesis? European Spine Journal. 2016;25(8):2408-15). (c) Springer-Verlag Berlin Heidelberg 2016. With permission of Springer.)

\section{REFERENCES}

I. Chaput C, Padon D, Rush J, Lenehan E, Rahm M. The significance of increased fluid signal on magnetic resonance imaging in lumbar facets in relationship to degenerative spondylolisthesis. Spine. 2007;32:1883-I887.

2. Rihn JA, Lee JY, Khan M, Ulibarri JA, Tannoury C, Donaldson WF III, et al. Does lumbar facet fluid detected on magnetic resonance imaging correlate with radiographic instability in patients with degenerative lumbar disease? Spine. 2007; 32:1555-1560.

3. Cho BY, Murovic JA, Park J. Imaging correlation of the degree of degenerative L45 spondylolisthesis with the corresponding amount of facet fluid. J Neurosurg Spine. 2009;II:6I4-6I9.

4. Snoddy MC, Sielatycki JA, Sivaganesan A, Engstrom SM, McGirt MJ, Devin CJ. Can facet joint fluid on MRI and dynamic instability be a predictor of improvement in back pain following lumbar fusion for degenerative spondylolisthesis? Eur Spine J. 2016;25:2408-24I5.

5. Schinnerer KA, Katz LD, Grauer JN. MR findings of exaggerated fluid in facet joints predicts instability. Clin Spine Surg. 2008;2I:468-472. that listhesis can be identified accurately. In developing countries where resources are already scarce and usually patients bear their own medical expenses, additional imaging workup for degenerative spine disease can be a burden on the patients' pocket. Spinal MRI is already an expensive test. Patients might save money for months before they can get a good-quality supine MRI done. Asking for additional tests can be a financial burden and can possibly delay treatment. For that reason, dynamic studies (usually radiographs) are often skipped, which leads to failure in identifying spinal instability correctly and may lead to treatment failure. The findings in the aforementioned study can potentially eliminate unnecessary investigations and focus financial resources where they are needed the most. This may result in improved compliance with treatment and a smaller number of patients lost to follow-up.

It is evident that facet joint effusion has a significant correlation with spondylolisthesis seen on radiographs. However, there is no prospective study to help clinicians understand this relation in detail. Also, it is important to establish temporality and improve our knowledge of disease pathology, to determine if facet joint effusion precedes the appearance of instability on radiograph or not. Calculation of sensitivity and negative predictive value of this marker are also required, so we can establish the clinical significance of this finding. This will help us to set the cut-off value for the facet fluid width, which will make the interpretation of this marker easier in clinical practice.

In conclusion, increased fluid in the facet joint serves as a predictor of spondylolisthesis and has the potential to serve as the most important screening test for the evaluation of degenerative disease of the spine and lumbar stenosis.

6. Caterini R, Mancini F, Bisicchia S, Maglione P, Farsetti P. The correlation between exaggerated fluid in lumbar facet joints and degenerative spondylolisthesis: prospective study of 52 patients. J Orthop Traumatol. 20II;I2:87-9I.

7. Lattig F, Fekete TF, Grob D, Kleinstück FS, Jeszenszky D, Mannion AF. Lumbar facet joint effusion in MRI: a sign of instability in degenerative spondylolisthesis? Eur Spine J. 20I2;2I:276-28I.

8. Mailleux P, Ghosez J, Bosschaert P, Malbecq S, Coulier B. Distension of the interfacet joints in MRI: and indirect sign of an existing underestimation of spondylolisthesis and canal stenosis. J Belge Radiol. I998;8r:283-285.

Department of Surgery, Section of Neurosurgery Aga Khan University Hospital, Karachi, Pakistan

1878-8750/\$ - see front matter (C) 2017 Elsevier Inc. All rights reserved. http://dx.doi.org/10.1016/j.wneu.2017.09.043 